\title{
Toward a low-carbon tourism for sustainable development: a study based on a royal project for highland community development in Chiang Rai, Thailand
}

\author{
Kampanad Bhaktikul $^{1} \cdot$ Sayam Aroonsrimorakot ${ }^{1,2} \mathbb{D} \cdot$ Meena Laiphrakpam $^{2}$. \\ Warit Paisantanakij ${ }^{2}$
}

Received: 17 December 2019 / Accepted: 6 November 2020 / Published online: 20 November 2020

(C) The Author(s) 2020

\begin{abstract}
Sustainable development of a community needs to be balanced in all dimensions. Global warming and climate change from human emissions can affect the development of communities including highland communities in Chiang Rai, Thailand in terms of human life, growth and yield of plants and animals. This research presents low-carbon tourism for the sustainable development of the rural highland community in Chiang Rai, Thailand by integrating economic, social and environmental objectives in community development for sustainability. This research is carried out through funding of a royal project and is based on mixed research methodology incorporating both qualitative and quantitative data analysis techniques in different stages including, ethnographic delphi future research, in-depth interview and observation. The study evaluates the community development levels standard and indicators for enhancing the community's economic development such as low carbon tourism development through analyzing the available resources and the Royal Project initiatives through education, meeting and discussion. The result shows its impact on four dimensions of development as 1 . environmentally friendly agriculture; 2 . forest restoration and conservation; 3. community health management; and 4. community strength to support change, to develop into sustainable low carbon highland communities. The results of this research can be used as a guideline for a sustainable low-carbon community development and also to evaluate criteria, indicators, as well as developmental steps for preparing and evaluating community development levels for certification of community development standards into low-carbon sustainable areas.
\end{abstract}

Keywords Low-carbon tourism $\cdot$ Sustainable development $\cdot$ Community development

Sayam Aroonsrimorakot

sayam.aro2560@gmail.com

1 Faculty of Environment and Resource Studies, Mahidol University, 999 Phutthamonthon 4 Road, Salaya 73170, Nakhon Pathom Province, Thailand

2 Faculty of Environment and Resource Studies, Center for Research Assessment and Certification of Environmental Management, Mahidol University, Salaya, Nakhon Pathom Province, Thailand 


\section{Introduction}

Global Climate change is considered a top priority problem for humanity and the ecosystem all over the world (Hoegh-Guldberg et al. 2019). It has created several impacts including extreme climatic hazards, disease outbreaks and environmental disruptions (Bastiaansen et al. 2020). This global climate change and its effect arise from human development activities and energy-related carbon dioxide emissions (Tobelmann and Wendler 2020). This made many scientists, researchers, policymakers and academicians of many countries to be concerned and search for new developmental steps to reduce $\mathrm{CO}_{2}$ emissions while maintaining sustainable economic development (Finance and Development 2019). Among these steps, the first developmental step which many countries have begun to initiate is low-carbon community development for sustainability. This step can be implemented in actions only through behavioral change, by practicing a low-carbon economy. Low-carbon tourism is a new concept that has been launched and promoted recently in the sustainable low-carbon economy, responsible tourism and development ( $\mathrm{He}$ and $\mathrm{Tu}$ 2020; Luo et al. 2016). Low carbon tourism is considered as a form of sustainable tourism that aims to achieve maximum tourism experience with low carbon technologies, less energy consumption, less $\mathrm{CO}_{2}$ emission and less pollution in the process for transportation, accommodation, sightseeing and other entertainment for economic, social and environmental benefits (Su 2019; Tang et al. 2011; Huang and Deng 2011). However, there were only a few studies on low-carbon tourism (Zhang 2017; Luo and Zhang 2011) and these studies were limited only on carbon dioxide emission caused by tourism industry such as emission due to food wastage, aviation, transportation, accommodation and recreation activity (Rico et al. 2019) and energy consumption in tourism, travel process, sightseeing, catering and tourist behavior (Backen, 2003). So, the tourism process and tourists are accountable for global $\mathrm{CO}_{2}$ emissions which is predicted to a yearly increase of 3.2\% during 2005-2035 (Peeters and Dubois 2010), along with massive waste generations and greenhouse emissions (Kuo et al. 2012). Even though in the recent decades' many tourists were responsible and willing to get carbon offsets, to neutralize emissions from travel, the adoption of carbon offsetting program has been reported to be very low (McLennan et al. 2014) and so cannot be relied solely on for the sustainable development of tourism industry (Scott et al. 2016a, b). So, policymakers, planners and academicians should conduct more studies to provide strategic management practice for sustainable low carbon tourism (Michailidou et al. 2015). Therefore, this research article aims to fill up the gap in the literature, because incorporating a low-carbon concept into a sustainable community development prototype will help to reduce a community's carbon footprint. The highland community in Chiang Rai, Thailand has a unique identity with productive forests and watershed resources with natural scenery and beauty, advantageous for tourist attractions and development if properly planned and guided. With this aim in mind, this article discusses the low-carbon tourism facilities available in rural areas of Chiang Rai, Thailand along with determining sustainable low-carbon highland community development standards of highland communities in Chiang Rai. The article is presented with the following objectives:

- To describe the available facilities of low-carbon tourism for sustainable development of the rural highland community in Chiang Rai, Thailand by integrating economic, social and environmental objectives for sustainable community development.

- To evaluate the economic, environmental and social impacts of the Royal Project to the highland communities for developing into a sustainable low carbon community. 
- To upgrade the highland communities in Chiang Rai as a prototype of low carbon sustainable community development.

\subsection{Description of the study area}

The study was conducted in Huai Nam Kuen village in Chiang Rai Province, Thailand, (Fig. 1) which is one of the highland communities included under the collaborative project of Huai Pong royal project development center, Mahidol university, Faculty of Environment and Resource Studies and Highland Research and Development Institute, Thailand. The origin and establishment of this village can be traced in 1882, which was discovered by a group of people from the neighboring village, Ban Sa-Khan-Hom who came to the forest and found a tea plant. Before the establishment of Huai Nam Kuen Village, the land was covered with dense forest with tea plantations in the surrounding area. They cleared the grass and tea plants in that area and settled down in the south of the village, about $200 \mathrm{~m}$ away from the present village. Over time, many villagers also moved into the present village as the space of their original village was small. This led to the establishment of a village named Huai Nam Kuen, Wiang- Pa-Pao district, Chiang Rai province, Thailand on September 13, 2000 and in course of time many other neighboring villages also were formed. The total area of Huai Nam Kuen village is about $12,000 \times 1,600 \mathrm{~m}^{2}$ and the total workplace and dwelling area are $2,000 \times 1,600 \mathrm{~m}^{2}$. Most of its inhabitants are Thai by Nationality and Buddhism by religion. The climatic condition in the region is very cold, especially in the winter season with temperature dropping as low as $0^{\circ}$ or lower than $0{ }^{\circ} \mathrm{C}$. Its distance from the Wiang-Pa-Pao district is approximately $53 \mathrm{~km}$. Currently, there are 118 households in Huai Nam Kuen Village.

\subsection{Literature review}

There are various concepts related to sustainable low-carbon community development such as low-carbon energy, low-carbon life, low-carbon society, low-carbon city, low-carbon community, low-carbon tourism, low-carbon world. An analysis of these various concepts is considered to be relevant to understanding more on sustainable low-carbon tourism for community development, as it would highlight their relationships and theoretical foundation (Yuan et al. 2011).

\subsubsection{Low-carbon development}

The concept of "low-carbon development" has been defined in various ways but the common feature is concerned with utilizing less carbon to promote economic growth in the

Fig. 1 View of Huai Nam Kuen village

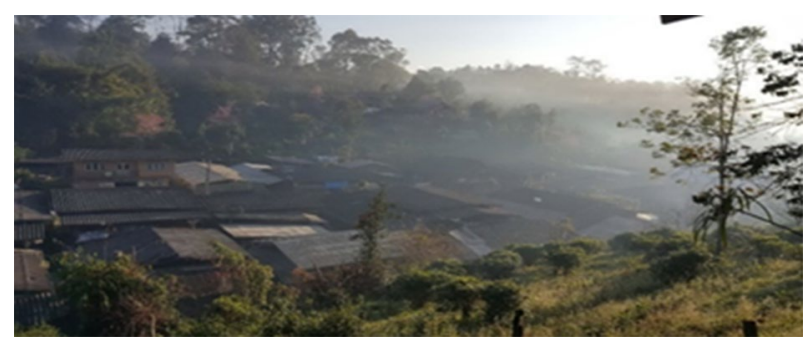


future (Mulugetta and Urban 2010). A low-carbon economy is the first phase of low-carbon development, with aims to reduce $\mathrm{CO}_{2}$ emissions by having a clear plan to promote low carbonization in a country's economic development, such as living with less consumption of natural resources, less environmental pollution and more economic products and to change the hardware (energy saving, emission reduction and recycled energy) as well as software system (government policy, management, regulation, index and ideology) (Huang and Deng 2011; Jin and Liu 2009; Yuan et al. 2011). This is followed by the second phase of having a low-carbon society, which includes low-carbon life, low-carbon culture, lowcarbon politics, etc. Once a community follows low-carbon lifestyles in all aspects including economy, daily life, politics and culture, it can be defined as a low-carbon community. To be a low-carbon community, societies should maintain low-carbon practices in its economy, daily life and culture (Jiang et al. 2013). After most countries in the world have become low-carbon societies, low-carbon development can be said to be matured and enter the third stage, that is, low-carbon world. Many instruments are needed to track the performance of low carbon development, such as carbon footprint (a measure of the impact human activities have on the environment in terms of the greenhouse gas produced, measured in tons of carbon dioxide), carbon label and carbon certification (Ridhosari and Rah$\operatorname{man} 2020)$.

\subsubsection{Low-carbon tourism}

Low carbon tourism is a new concept proposed recently in 2009 as a form of sustainable tourism that aims to achieve maximum tourism experience with a new way of a travel plan for the tourist and tourism industry to acquire higher social, economic and environmental benefits for our society by reducing carbon emissions occurred in tourists' activities (Wang et al. 2019). Low-carbon tourism and low-carbon industry are indivisible components of the low-carbon economy especially in the recent decades, as we are witnessing environmental, behavioral and socio-cultural impact in many regions due to the rapid global expansion of tourism and tourists' activities such as carbon dioxide emissions due to the consumption of energy in transportation, operation and development of infrastructures. Some of the examples are hotel construction, airways, roadways, railways, heating, cooling equipment and various other leisure activities. In this way, tourism activities resulted in global warming and climate change. However, global carbon emissions related to tourism are not well quantified. It is said in one study that of the total global greenhouse gas emissions, 5\% is contributed by tourism (Gossling 2013; Scott et al. 2016a, b), while another recent study reported $8 \%$ of the total global greenhouse gas emission (Lenzen et al. 2018). Due to this global impact, there is an increasing concern globally of environmental problems caused by carbon footprints of tourism activities.

\subsubsection{Community development}

Having defined the various related concepts connected with the title of the study, let us define the concept of "community" and "community development" Flora and Flora (1993). defined a "community" as a group of people bound by geography and with a shared destiny, such as a municipality or a town. Jim (2015) defined community development as a process conducted by community members with aims for local people to not only create more jobs, income and infrastructure but also help their community to be able to manage change. Community development is based on five capitals of a community-social, 
human, financial, physical and environmental. Social capital is built through people's participation in their community activities or organizations, problem solution and creating networks or relationships. Human capital is generated by people's increasing knowledge and new skills, along with maintaining good physical health and developing financial capital. With this, they can also manage their lifestyles to improve their environment. Employment generation and infrastructure development are the major aims of community development and these can be achieved through people's changing attitudes, mobilizing existing skills, improving relationships, thinking creatively for problem solutions and using community resources for sustainability. Therefore, the success of community development depends on the interaction between people and unified action, that is, collective solidarity commonly called by sociologists, rather than individual activity (Flora and Flora 1993).

\subsubsection{Sustainable development}

Sustainable development has been defined in various ways by various scholars. However, the most commonly accepted one is the definition of Brundtland Report (Brundtland 1987) which is defined as "meeting the needs of the present without compromising the ability of future generations to meet their own needs." Opoku and Ahmed (2013) provide another modified definition as "The adjustment of human behavior to address the needs of the present, without compromising the ability of future generations to meet their own needs" (p.43). Therefore, sustainable development is closely associated with economic growth and environmental resource protection for the future.

\subsubsection{Low carbon tourism strategies, travel and global climate change}

It is increasingly recognized from the review of literature that tourism and travel have a growing role in global climate change with an emphasis on the importance of behavioral changes for altering the impact of tourism on the environment, such as promoting tourism with less carbon emission. Some studies focus on the development of low-carbon tourism to discover the path, strategies, role of government organizations, tourism enterprises, practices and application of low-carbon tourism for sustainable development through strategic planning (Cui and Liu 2014; Li et al 2013). There are two types of carbon dioxide emissions from tourism: direct (fuel and energy consumption, accommodation, electricity or gas consumption, restaurants and other tourist activities) and indirect emissions (energy-producing and transportation infrastructure, manufacturing of vehicles and construction of the accommodation or restaurant facilities). When calculating the indirect impacts are normally not included in carbon footprint calculations (Fang 2011). Also, life cycle assessment is used in a study in Taiwan to measure environmental impact assessment due to tourist in tourism activities and found tourist usage per trip as $1606 \mathrm{MJ}$ of energy, $607 \mathrm{~L}$ of water and emits $109,034 \mathrm{~g}$ of $\mathrm{CO}_{2}, 2660 \mathrm{~g}$ of $\mathrm{CO}, 597 \mathrm{~g}$ of $\mathrm{HC}, 70 \mathrm{~g}$ of NOx along with generation $416 \mathrm{~L}$ of wastewater, $83.1 \mathrm{~g}$ of BOD and $1.95 \mathrm{~g}$ of solid waste. The highest emission is caused by transportation (67-72\%) and air transport alone releases about $43 \% \mathrm{CO}_{2}$ (Kuo and Chen 2009; Peeters and Dubois 2010). As a result, low-carbon tourism is increasingly promoted and becoming familiar in many countries around the world such as building a low-carbon city in Copenhagen, Denmark, launching of low-carbon hotels in Koh-Samui, Thailand and Bintan, Indonesia, building scientific museum based on low carbon theme in California, USA (Huang and Deng 2011). Implementation of low-carbon tourism require certain 
strategies, including bringing awareness through mass-media in every minor detail used in the process and changing them with alternative means with less cost and less emission such as replacing paper with e-ticket, tourists bringing their bags, avoiding usage of disposable tableware, using green energy transportation for tourists travel and so on (Changbo and Jingjing 2011).

According to Huang and Deng (2011), the main emphasis of low-carbon tourism is that energy consumption and Carbon dioxide emissions caused by tourism activities, products and services are minimized. It is said in the Energy White Paper that the lowcarbon economy is trying to create higher standards of living by less consumption of natural resources, less environmental pollution and more economic output. Their study further pointed out that the path to developing low-carbon tourism is reducing the carbon footprint by creating low-carbon tourist attractions, allocating low-carbon tourist facilities, promoting a low-carbon way of tourism consumption and nurturing a tourism experience environment of carbon sequestration. Some of the strategies are:

(a) Creating low-carbon tourist attraction: It is concerned with the tourism industry's role in planning and designing the scenic area and tourist destination to form a model of recycling development and circular economy. It should be carried out through ecolabeling act, repair and protect natural landscapes such as forests, grasslands, beaches, etc. to maintain its original ecological state.

(b) Role of tourist administrative department in low-carbon tourism development: It is concerned with the enactment of laws and regulations for the promotion, standardization and institutionalization of low-carbon tourism for environmental protection, by strengthening the low-carbon implementation system of tourism-related business through stricter low-carbon standards for tourist attractions, tourism transport and tourist hotels (Luo and Zhang 2011). The government should encourage tourism enterprises to develop energy conservation, reduce carbon dioxide emissions and use renewable energy. At the same time, the government should support the economic hardship of tourism enterprises by tax reduction, fiscal subsidies, government procurement and green credit. There should be special funds for implementing the low-carbon tourism project of enterprises for developing low-carbon projects. The government should also increase the environmental awareness of the public on understanding the low carbon tourism and promote the public initiative to low-carbon tourism. Besides, international cooperation in a low-carbon economy should be initiated to promote the competitiveness of the tourism industry by adopting advanced management.

(c) Role of the travel agency: Travel agency should help in propagating low-carbon tourism and develop low-carbon tourism products and routes to meet the needs of tourists. For instance, travel agencies can properly design hiking and bicycle travel routes to guide tourists return to nature, love nature, protect nature, in a bid to reduce carbon emissions and maintain the sustainable development of tourism.

(d) Role of tourism hotels: Tourism hotels should greatly raise the level of low-carbon management through the establishment, demonstration and popularization of green standard comprising of saving energy, cutting down the consumption of raw materials, environmental protection, green procurement, green marketing. The hotels should use low-carbon technology, new materials and intelligent control system in construction, heating, air conditioning, lighting, electrical use and water use and so on to save energy and reduce carbon footprints by using alternative energy such as solar energy. 
(e) Role of Tourist: The tourists should be made aware of the benefits of low carbon activity through advertisement in the tourism process of catering, accommodations, transportation, sightseeing, shopping and entertainment.

(f) Implement a Carbon Offset Program: The most important way to promote low-carbon tourism consumption is to implement a carbon offset program to visitors (McLennan et al. 2014). On one hand, we can use forests, oceans, wetlands and other natural resources as a vehicle to offset carbon. For example, we can promote tourists to plant trees. Besides, airways can reduce fuel consumption by decreasing the capability of the water tank to make the plane lighter. Certainly, the development of alternative fuels, especially biofuel, is a long-term measure to save energy and reduce emissions. Buses, electric cars, bicycles and other low-carbon or carbon-free transportation modes should be encouraged and promoted. In this way, low-carbon traffics can significantly reduce the emissions of greenhouse gases, carbon monoxide and pollutant particulates. Similarly, Kumar et al. (2016) made a project study in Thailand at AIT, on the sustainable urban tourism through low-carbon initiatives in two cities, Hue in Vietnam and Chiang Mai in Thailand with aims to explore how to achieve greenhouse gas emissions reduction through low-carbon tourism initiatives. It estimated greenhouse gas emissions in the tourism sector of the two cities and concluded advocating non-motorized transport (NMT) in Chiang Mai Municipality while promoting garden houses in Hue. Both cities had the potential to reduce emissions as well as generate jobs, increase income and provide a cleaner environment for visitors and the local community.

\section{Methodological approach}

The above review of literature has led to the theoretical framework of this article, which is based on "community resource" through community-based low carbon tourism initiative as initiated by Scheyvens (1999). The pyramid showing the dimensions of sustainable development, as shown in Fig. 2 and the Community Resource Framework as shown in Fig. 3 are adopted as the frameworks to examine the low-carbon initiative and facilities-resources (personal, socio-cultural, organizational and infrastructural) available in Huai Nam Kuen Village in particular. Also, a comparative evaluation of 12 highland participating communities' development into four dimensions covered by Royal Project Development Centers in Chiang Rai, including Huai Nam Kuen Village Community was conducted previously as shown in Fig. 5. The indicators in the four dimensions are used to analyze the impacts of low carbon tourism to the participating highland communities in Chiang Rai, Thailand.

\subsection{Procedure of data collection and evaluation}

The present study was carried out by the researchers of Mahidol university, Faculty of Environment and Resource Studies in collaboration with Huai Pong Royal Project Development Center and Highland Research and Development Institute, Thailand. The Royal Project was funded and initiated by His Late Majesty, King Bhumibol Adulyadej of Thailand since 1969 with aims to improve the lifestyles of hill tribes or highlander communities through sustainable forests and water resources. In 1992, His Late Majesty graciously upgraded the status of the Royal Project to become The Royal Project Foundation (TSDF 2018) with aims to bring a balanced sustainable growth in all dimensions, with special focus on incorporating practices for reducing greenhouse gas emissions, to slow down the 


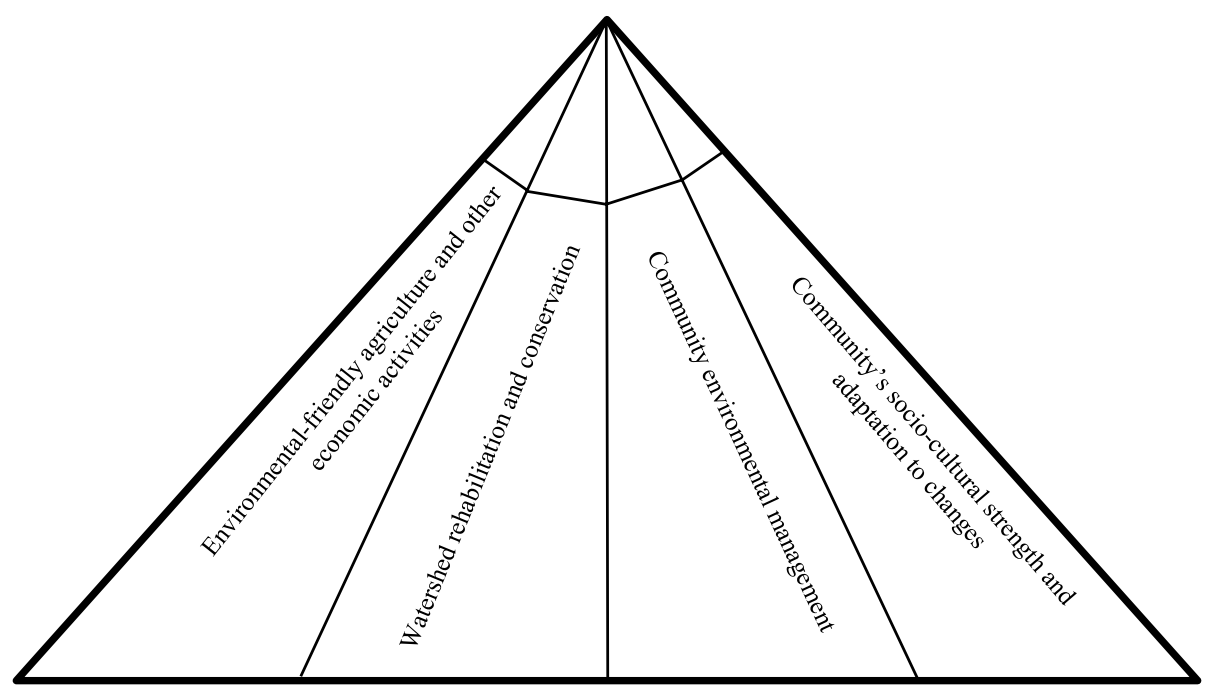

Fig. 2 Pyramid showing dimensions of sustainable development in Chiang Rai

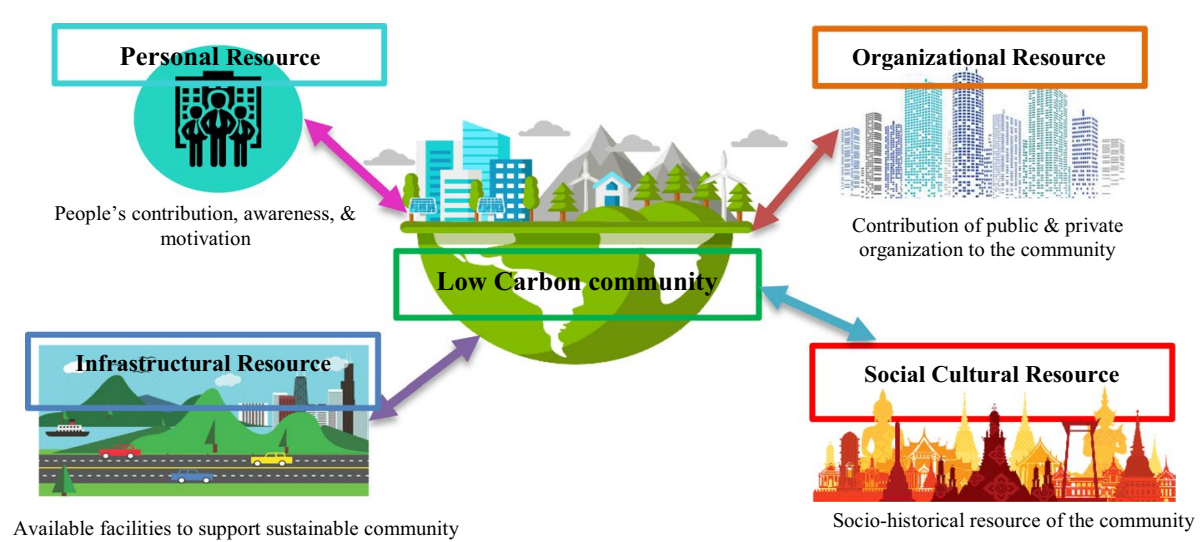

Fig. 3 Community resource framework

global warming and climate change. In January 2018, the low carbon team went to the study area, Huai Nam Kuen village, Chiang Rai from January 15-17, to observe and interact with the highlander community of the village along with training of participating officers and committee members of the region for mobilizations on low-carbon capital, both natural and social, low-carbon economy, low-carbon tourism, low-carbon society and lowcarbon lifestyles to recognize the growing importance of low-carbon tourism for community's economic development through education, meeting and discussion. In the first phase of developmental attempts, 11 Royal Projects were covering 12 highland communities in Chiang Rai. The Royal Project Foundation and Highland Research and Development Institute played an important role, as a consultant of the various developmental activities and tourism operations to bring standards with the development of infrastructures of tourism and availabilities of all facilities to the touring group. Secondary data of previous research 
reports is also obtained from the project Coordinator of Highland Research and Development Institute, Thailand regarding the evaluation of 12 communities level of development in 11 areas of the Royal Project Development Centers in Chiang Rai by comparing the development standards of 4 dimensions in a year. The research used mixed research methodology incorporating both qualitative and quantitative data analysis techniques in different stages. Firstly, it employed ethnographic delphi future research (EDFR) technique of data collection, a combination of ethnography (Van Maanen 1996; Genzuk 1999), that is, the main methods of collecting data were through observations, interviews and some documentary archives and delphi studies (collected from a panel of community experts belonging to different strata, professions and organizations in Thailand. For EDFR technique, the stages employed were as:

\section{Defining and preparing expert groups}

Expert group, consisting of two academicians from the Faculty of Environment and Resource Studies, Mahidol university, two from Royal Project Foundation, two from Highland Research Development Institute, two Royal Project community leader and seven committees of experts (third party) having expertise in various fields. Details of the names of the experts and their organizations were kept confidential). It is more reliable because instead of using a sampling technique to represent a certain population, a group of experts and stakeholders with a deep understanding of the subjects are chosen to answer the questionnaire (Dalkey and Helmer 1963; Ziglio and Adler 1996.)

\section{Selecting the participants}

Selected Royal Project communities that voluntarily participate in the project, consisting of 4 highland areas which grow Miang or tea leaves under four Royal Project Development Centers as Pa Miang, Teen Tok, Mon Ngo and Huai Pong; 2 rice growing highland areas under two Royal Project Development Centers as Mae La Noi and Thung Roeng; and 5 opium cultivating area under five Royal Project Development Centers as Nong Hoi, Mae Hae, Mae Sapok, Ang Khang and Inthanon.

\section{Surveying the selected area}

Survey the area to assess the level of development of the initial participating community project to determine the framework for establishing standards for community development on highland low-carbon sustainable community development. There are 4 components criteria for low carbon sustainable community development assessment as:

1. Environmentally friendly agriculture; 2 . Forest restoration and conservation; 3 . Community health management; and 4 . Strength of the community to support changes.

4. Creating tools for data collection.

The researcher used explicit criteria to select a panel of 15 experts and designed a well-structured questionnaire concerning the issue under consideration. Panelists were then asked to respond to the questionnaire during a series of rounds and all responses were obtained individually and anonymously. Detailed guidelines on how to select the group of experts suitable for the Delphi study were explained by many scholars (Delbecq and 
Van de Ven 1971; Okoli and Pawlowski 2004; Avella 2016). The researchers contacted the experts and explained to them the study subject and asked them to complete the questionnaire. Besides this, the researcher obtained additional in-depth information through telephone interviewing from three key informants, who were the actual beneficiaries of the Royal Project, who occupied positions as heads of the village and who were willing to spare time to provide information. These three key-informants were recommended by the coordinator of the Highland Research and Development Institute, Thailand. After the responses were received, the researchers analyzed the responses by narrowing down the original list with all answers to a list with the most important answers. The data were then analyzed quantitatively to determine the ranks of the items on the list as well as qualitatively in terms of response quotation.

\section{Results and discussion}

\subsection{Low-carbon tourism in Huai Nam Kuen village}

In 2013, the community recognized the growing importance of low-carbon tourism and prepared itself for the community's economic development as it has a unique identity with productive forests, watershed, natural beauty and follows the philosophy of a sustainable self-sufficient economy and learning center of His Late Majesty, King Bhumibol Adulyadej, with aims to continue to have a harmonious, happy and peaceful life. So, with the cooperation and assistance of Huai Pong Royal Project Development Center and Highland Research and Development Institute, the community prepared itself for tourist homestay to accommodate tourists for development. The first tourist home, Ban Huai Nam Kuen Homestay, was set up to welcome the touring group (Fig. 4).

In the first phase of development activities, the Royal Project Foundation and Highland Research and Development Institute played an important role as consultants of the various developmental activities and tourism operations to support the touring group and to develop the community infrastructures and facilities to a standard. In 2015, Ban Huai Nam Kuen homestay had passed the Thai homestay standard certification from the department of tourism. And in the following phase, a group of Huai Nam Keun homestay aims to develop community tourism to obtain other standards including network creation to make sustainable tourism by their community. The following are some of the features of lowcarbon tourism development available in the region:

1. Agricultural tourism: Here, the tourist can visit the orchard such as sweet passion fruit, cape gooseberry and avocado berries, flowerbeds such as cymbidium, orchid, potted
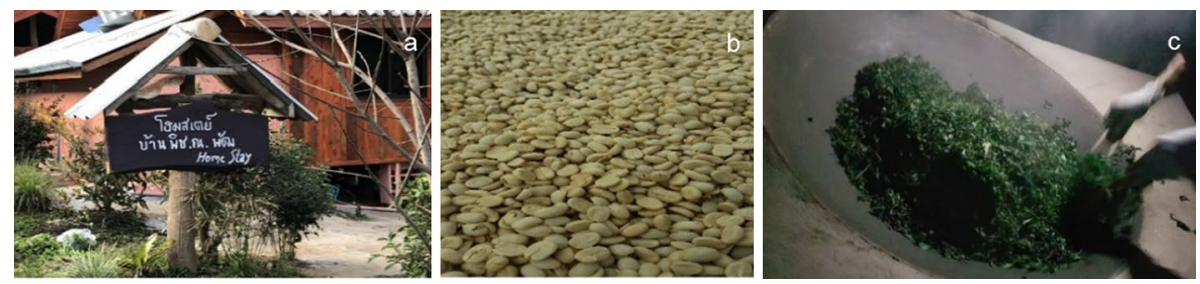

Fig. 4 a Ban Huai Nam Kuen homestay b Processing of coffee and $\mathbf{c}$ Processing of tea 
plants, beverage plants such as tea and coffee, medicinal plants, a backyard garden along the roadside and the front yard of each household and also local plants such as wild custard apples.

2. Cultural tourism: The tourist can visit the households to see the way of living, occupation, income and means of livelihoods of the communities and interact with the local community people to observe how to store, roast, bind and ferment tea leaves, coffee and other herbs. In addition, they can observe and learn other conventional traits such as method and procedure of making a specific formula of spicy chili, food processing from dried coconut, the performance of local arts and cultures such as Thai sword dancing and local music. The tourists can buy as souvenirs local products such as tea, dry fruits, handicrafts product, etc. and at the same time experience natural tourism by walking along the natural footpath of Doi Mod- Doi-Chang to watch the Azalea roses, the diversity of vegetation that grows up in the forest region at altitudes ranging from 1,000 to 1,700 m above sea level and a variety of birds living in the wild surrounding areas.

\subsection{Low-carbon economy: community products, facilities, other infra structures}

Following are some of the community agricultural products, facilities and infrastructures as:

1. Tea and coffee 2. chili paste 3. passion fruit juice, dried gooseberry, dried coconut products, etc. There are currently, 11 homestays or guest houses, 10 tents, 6 sleeping bags and 4 convenience stores. For the convenience of the travel of tourists, there is shuttle bus service plying from Khun- Chae National Park to Ban Huai Nam Kuen at 800 Baht per round trip. The distance of the community village to Chiang Mai is around $68 \mathrm{~km}$ and it takes about one and a half hours to travel by roadways along highway 118 .

\subsection{Integration of research and development work in highland community of Thailand}

The following table gives the detail of indicator, unit, evaluation criteria for the highland community integrated research and development plan for low-carbon prototype communities in Thailand. Assessment of the community's performance is based on a report of meetings or seminars and reports (Table 1).

\subsection{Evaluation results}

The article also presents the evaluation of economic, environmental and social impacts of the Royal Project to 12 participating highland communities in Chiang Rai for developing into a sustainable low carbon community standard. The development levels were categorized into four dimensions as (1) Environmental-friendly agriculture and other economic activities, (2) Forest restoration and conservation, (3) Community health management and (4) Community's social unity, strength and adaptation to changes. The development level of the 12 communities in 11 areas of the Royal Project Development Centers was evaluated by comparing the development standards of the above 4 dimensions in 12 months. The evaluation criteria for determining the standard of sustainable low carbon highland community development consist of 19 items and 32 indicators as given in Fig. 5. 


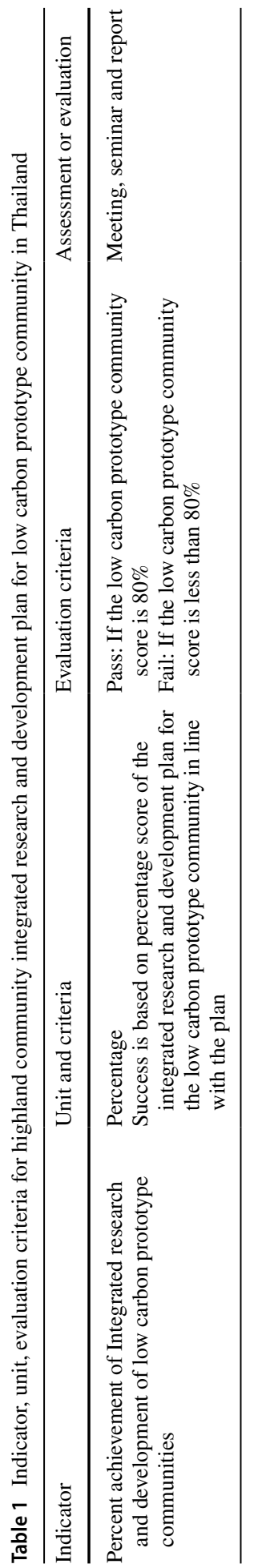




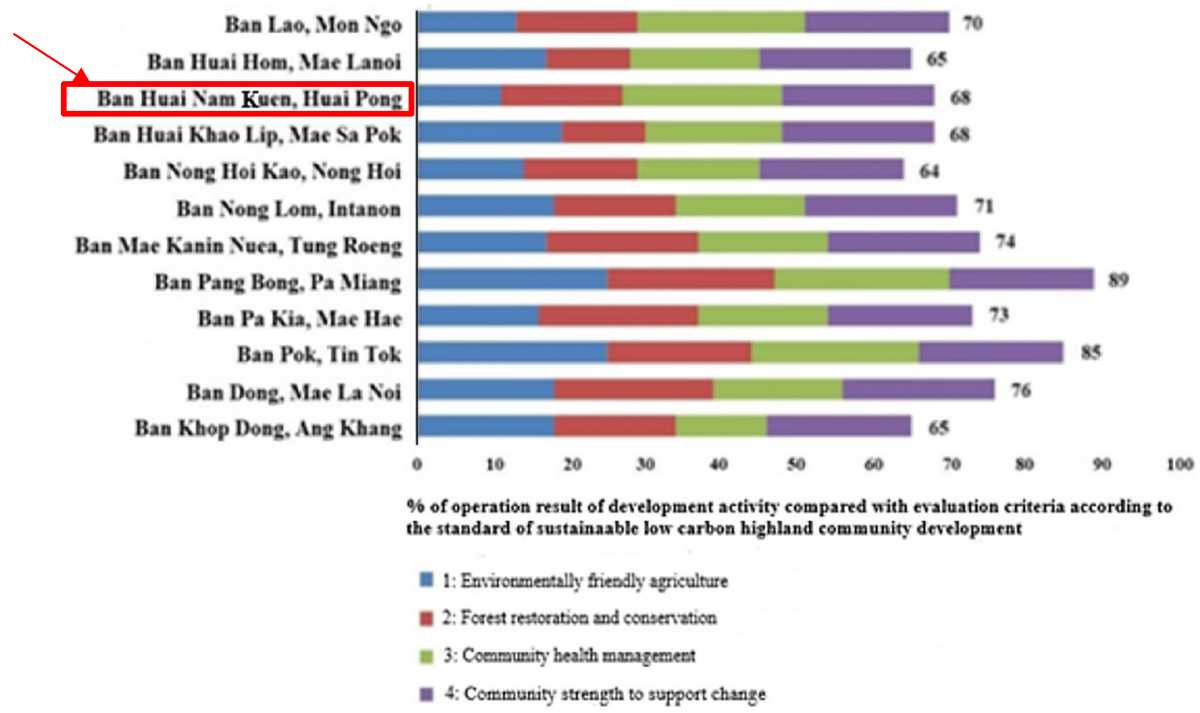

Fig. 5 Evaluation of 12 Communities development levels in 11 areas of the Royal Project Development Centers by comparing the development standards of 4 dimensions in 12 months (Mensin et al. 2018)

From the evaluation result, it was found that the development resource of these highland communities, being located at a faraway distance from the city, was based on natural agricultural resources and the environment. It was found that Ban Pang Bong has the highest development level (89\%), followed by Ban Pok, Ban Dong, Ban Mae Kanin Nua and $\mathrm{Ban} \mathrm{Pa} \mathrm{Kia}$ (85, 76, 74 and 73\% respectively) as shown in Fig. 5. However, some development activities had to be operated as a solution of the prevailing problem and to promote development and among these were 7 indicators, consisting of drip irrigation of vegetables, livestock farm certification, determination of forest boundary and agricultural areas, community water quality, household wastewater quality, sewage management from livestock farm and wastewater quality from livestock farming and these require cooperation from members of the community.

\subsection{In-depth interview result}

Furthermore, the authors have collected additional data through telephone in-depth interviewing from three key informants, holding positions as heads of the village, who were the actual beneficiaries of the project and who were willing to spare time to provide in-depth-information related to the project. These three key informants were recommended by the coordinator of the Highland Research and Development Institute in Chiang Rai, Thailand. The following were the questions asked to the respondents during the telephone interview. The summarized interview quotes are given below:

1. Could you please tell me something about the Royal Project initiative for low carbon tourism? 
The project is beneficial to the community both environmentally as well as economically. First of all, the project helps our village to provide better facilities for imparting education, development in roads, transportation leading to infrastructure development for tourist access, economic development and an overall improvement in the status of earning and living to become a sustainable community. At the same time, the project makes us aware that our community is responsible in improving air quality to be passed to all lower-areas of the country and it helps us to provide jobs or source of income, improving the economic status and provides many facilities to develop into a sustainable community too.

2. What development work is done in your village by the Royal Project in terms of promoting low carbon tourism and to develop a sustainable economic condition of the local people?

Initially, our village has no scientific knowledge of innovative agricultural practices, but after the arrival of the Royal Project in our village, many initiatives have been done to improve agricultural practices and we have learned lots of knowledge about innovative agricultural management. Due to this project, the agricultural process is easier, more systematic and at the same time have increased in the output of agricultural and processed agricultural product, such as we learned new techniques of food drying, coffee or tea processing, dry fruits preserving and packaging to be sold internally as well as externally. We also have an innovative waste management system. Generally, most people in the village do not separate waste at home, especially waste that contains lots of plastic bags, kitchen waste, solid waste and other hazardous waste. Thai people are generally used to receiving services from local government, especially solid-waste management, almost free of charge and generally, ignore their roles in improving the situation themselves. This inevitably leads to questions of management efficiency, cost recovery and accountability, so that all food wastage, agricultural or other solid wastage could be sorted out into recyclable or non-recyclable, by the initiative of Royal Project and ultimately leading the community to maintain the standard of being a low carbon community for sustainability.

3. Could you please tell the social and environmental impact of the Royal Project to the local community?

In my opinion, there is so much social impact in our community after the arrival of the Royal Project. Our village is a small village and the organization is to live like a large family, having mechanical solidarity, where everybody helps each other and knows each other. But with the arrival of the Royal Project, economic activities expanded and people have more opportunities to pursue other occupations besides agriculture such as the opening of Homestay for tourists. Besides, the Royal Project make an initiative to impart better education, health care, development of roads and transportation, along with the provision of economic facilities and this has a social impact in terms of the avenue of tourist infrastructure, travel, accommodation and other site seeing facilities along with the development of NGO organization, beside the Royal Project membership and so on. Also, this project makes the villagers have more public responsibility especially innovation in agricultural product processing, food packaging and broadened other occupations with the availability of other sources of earning or economic pursuits in our community. Similarly, our community has changed to be environmentally friendly, as we learned about waste management, waste sorting, wildfire protection, organic farm, eco-tourism and so on. We gained knowledge of 
environmental management, such as reforestation, watershed forest preservation, trash sorting, soil improvement through composting and wildfire protection.

4. Are you involved in this Project? What about your neighbors and others? Do you think the project is successful in developing the community? What are the factors that make the project successful?

Since we are the heads of the village group, we have responsibilities for the welfare of other inhabitants of the village who are involved in this project. From this project, we have received lots of knowledge and idea to manage our farm, environmental care, such as reforestation, trash sorting and reducing and monitoring hot spots, watershed forest and conducted day to day observation of other residents in the village to prevent some people from disagreement or violation from measures of environmental protection in the village. This project is successful in helping the highland village and among the many factors responsible for its success is warm cooperation from the co-villagers in implementing sustainable community activities and due to this sustained hard work and attempts our community got the distinctive patronage award from the Royal Project Foundation.

5. What tourism facilities are available in your village? Who are the tourists, its numbers increased or not? Why?

Currently, since our village is located in the highland region with backward roadways and no airways, which is difficult for tourists to reach the place, there were only a few tourists, comprising of mostly of Thai and a few foreigners, visiting to explore the region. We have homestays and eco-friendly tourism facilities. The number of tourists is not increasing as our village is located at a high altitude, far from the city and quite backward in terms of roadways and other traveling facilities, which made the tourists travel a long time, after facing the rugged terrain and zig-zag road to reach the village and there are only 10 homestays available in the village so far and these could accommodate only 50 tourists per day who came there especially for adventure and excavation of the culture and ways of life of the folk people of the community. However, with the arrival of the Royal Project Foundation, we have improved in hand made arts and crafts making of the community villagers, such as we make and design agriproduct souvenirs, homestay and eco-tourism facilities.

6. If there is no tourist in your homestay, what sort of occupation will you do? Is there any improvement in earning and other economic facilities after the Royal Project initiative?

Most of the villagers are engaged in agricultural activities, by occupation. Most of us have tea farm and the produced tea are processed into fine products, called Cha ha See (five colors tea), consisting of five colors tea as white, green, yellow, black and red. In addition to tea farming, we grow other fruits like avocados, bananas and oranges. However, we get the highest source of income from the tea plantation. We also received training and innovative education to produce and process fine quality agriproducts to earn more extra income from the Royal Project Foundation.

7. What factors do you think will make local people supportive of low-carbon tourism for community development? What do you think is the role of government for developing low-carbon tourism for low carbon community development in your village? 
The factors for the success of low carbon tourism for community development in our village are having or promotion of stable and secured occupation, income, along with other villager's cooperation, promotion of environment-friendly agricultural practices, or other eco-tourism promoting activities. In this regard, cooperation among the residential houses in the village is very important for the implementation of the Royal Project initiative to develop into a low-carbon community for sustainable development. Sometimes, differences among us arise and this is the only obstacle, but it is generally settled and solved through mutual discussion and negotiation among us to proceed to further development of the community. Besides this, the government of Thailand should allocate funds for the development of government hospital in the highland region near our village because the existing hospital is located quite far away from our village, which is quite difficult for us to access during an emergency at night or during the rainy season as already mentioned in a previous study (Bhaktikul et al. 2019).

The above analysis of Huai Nam Kuen community shows that the available resources, comprising of low-carbon economy, low-carbon tourism facilities, low-carbon culture, lifestyles and other resources available in the region can be utilized to sustainable low-carbon community development. The result found that participation of the community and its supporting agency, comprising of both public and local organizations were important factors to promote sustainable low-carbon community development in the region. From the interview with key-informants, sometimes differences exist among the community inhabitants concerning the distribution of financial resources. This is because, in a small community like Huai Nam Kuen community, political differences causing different political groups often arise. Such conflict of interest within the communities may hinder the integration of the community's low carbon development. About the economic impact of low-carbon tourism for the community development, there is not much economic impact since the number of tourists visiting the region is unstable and not much, depending on the available infrastructure resources, such as available homestay, roadways and other backward traveling facilities, difficulties in accessing the region during heavy rainfall and other climatic condition. Despite it, it provides additional employment to many inhabitants of the community, such as opening restaurants to serve the guests, as tour guides, packaging and selling souvenirs of tourists, as different types of tea in different colors, owning accommodation as a homestay for tourists to stay and so on. These generate more income for the community people besides the agricultural contribution.

\section{Conclusion and recommendations}

Thus, promoting low carbon tourism facilities along with low carbon economy initiatives by the Royal Project can generate more employment and income-earning opportunities besides the normal low carbon agricultural practices of the community people. Low-carbon tourism for sustainable community development depends on the available economic, environmental, social and cultural strength and practices of the community and this too has an impact on the economic, social and environmental dimensions of the community. It can be concluded at the end that low-carbon community development which is an integral part of a society's sustainability is closely related to all dimensions of development. The study, therefore, provides an in-depth insight into the contribution of the Royal Project Foundation to upgrade the highland communities in Chiang Rai as a prototype of low carbon sustainable community development by bringing the environmental, economic and social 
dimension of sustainable development, leading to the conceptual development foundation for preparing and evaluating community development levels for certification of community development standards into low-carbon sustainable communities. Finally, low-carbon tourism can be adopted as an alternative form of tourism with the least environmental impact for sustainable development of a community because low-carbon tourism has a multidimensional beneficial impact to a community in terms of social, economic and environmental benefits along with reducing carbon emissions occurred in tourists' activities.

The review of literature recommended the need for behavioral change for the tourist administrators, operators, agencies as well as the tourists themselves to lead to low-carbon tourism for sustainable development. Besides, to promote sustainable development in the region, the community should be prepared to obtain the certification of environmental management as a low carbon sustainable community. This needs improvement in waste management, irrigation and agricultural practices. Mention can be made of some development activities that the community cooperated for improvement or development of the region such as using new techniques in irrigation and agricultural farming, including drip irrigation, mini-sprinkler, using rubber tube, livestock farm certification, demarcation of forest and agricultural areas boundary, adding chlorine for sterilization, plant culture, waste absorption from household by plantation culture, setting the wastewater treatment plant, sewage management method and improvement from livestock farming before releasing and building the bio-fermentation tank and so on. Development activities that need to be upgraded include 7 indicators such as, water-saving, good animal practice, demarcation and maintenance of forest boundaries, water supply quality, wastewater quality, wastewater management from livestock farms, livestock wastewater quality and its management requires the cooperation of community members. From the above analyses, it shows that low carbon tourism initiative promoted by the Royal Project Development Center can foster Huai Nam Kuen village into a sustainable low carbon community along with the practice of low-carbon economy, behavioral changes and co-operations from all concerned agencies including government lawmakers, tourism enterprise, administrator and local organizations.

Acknowledgements This work was supported by grant from Government Budget, Mahidol University, Contract No.14/2561, dated March 16, 2018. The authors would like to thank Mahidol University, Huai Pong Royal Project Development Center and Highland Research and Development Institute, Thailand for their support and the participants from Huai Nam Kuen Village, Chiang Rai, Thailand for their valuable comments in providing valuable data and other information.

\section{Compliance with ethical standards}

Conflict of interest The authors declare that there is no conflict of interest.

Ethical treatment of experimental subjects (animals and human). None.

Informed consent Informed consent was obtained from all participants included in the study.

Open Access This article is licensed under a Creative Commons Attribution 4.0 International License, which permits use, sharing, adaptation, distribution and reproduction in any medium or format, as long as you give appropriate credit to the original author(s) and the source, provide a link to the Creative Commons licence, and indicate if changes were made. The images or other third party material in this article are included in the article's Creative Commons licence, unless indicated otherwise in a credit line to the material. If material is not included in the article's Creative Commons licence and your intended use is not permitted by statutory regulation or exceeds the permitted use, you will need to obtain permission directly from the copyright holder. To view a copy of this licence, visit http://creativecommons.org/licenses/by/4.0/. 


\section{References}

Avella, J. R. (2016). Delphi panels: Research design, procedures, advantages and challenges. International Journal of Doctoral Studies, 11(1), 305-321.

Bastiaansen, R., Doelman, A., Eppinga, M. B., \& Rietkerk, M. (2020). The effect of climate change on the resilience of ecosystems with adaptive spatial pattern formation. Ecology Letters, 23(3), 414-429.

Becken, S., Simmons, D. G., \& Frampton, C. (2003). Energy use associated with different travel choices. Tourism Management, 24(3), 267-277.

Bhaktikul, K., Aroonsrimorakot, S., Laiphrakpam, M., Metadilogkul, O., \& Konjengbam, S. (2019). Indicators of active ageing for sustainable development: A comparative insights of ageing elderlies from Chiang Mai (highland) and Nakhon Pathom (lowland) Provinces. Thailand. Interdisciplinary Research Review, 14(5), 39-46.

Brundtland, G. H. (1987). Our Common Future World Commission on Environment and Development $(W C E D)$. Oxford: Oxford University Press.

Changbo, S., \& Jingjing, P. (2011). Construction of low-carbon tourist attractions based on low-carbon economy. Energy Procedia, 5, 759-762.

Cui, L. \& Liu, H. (2014). Study on the Development of Low Carbon Tourism in the Era of Low Carbon Economy, In Advanced Materials Research (Vols. 962-965, pp. 2343-2346). Trans Tech Publications.

Dalkey, N. \& Helmer, O. (1963). An experimental application of the delphi method to the use of experts. Management Science, 9(3): 458-467. Retrieved from ocsci2.ucsd.edu/ aronatas/project/academic/delphi method of convergence.pdf

Delbecq, L., \& Van de Ven andrew, H. (1971). A group process model for problem identification and program planning. Journal of Applied Behavioral Science, 7(4), 466-492.

Fang, Y. Ch. (2011). Is low carbon tourism a good incentive for the development of a low carbon community? - A case study of the Pinglin District. MA Thesis, Lund University. Retrieved from www. lumes.lu.se/sites/lumes.lu.se/files/fang_ying_chen_thesis_2011.pdf.

Finance and Development. (2019). The Economics of Climate. Retrieved from https://www.imf.org/exter nal/pubs/ft/fandd/2019/12/pdf/fd1219.pdf

Flora, C. B., \& Flora, J. L. (1993). Entrepreneurial social infrastructure: A necessary ingredient. The annals of the American academy of political and social science, 529(1), 48-58.

Genzuk, M. (1999). A Synthesis of Ethnographic Research. Los Angeles: Metropolitian Project/ARCO Foundation.

Gössling, S., Scott, D., \& Hall, C. M. (2013). Challenges of tourism in a low-carbon economy. Wiley interdisciplinary reviews: Climate change, 4(6), 525-538.

He, J., \& Tu, X. (2020, June). On Sustainable Development of Low-carbon Tourism in Jiangxi Province. In Journal of Physics: Conference Series (Vol. 1549, No. 2, p. 022134). IOP Publishing.

Hoegh-Guldberg, O., Jacob, D., Taylor, M., Bolaños, T. G., Bindi, M., Brown, S., \& Engelbrecht, F. (2019). The human imperative of stabilizing global climate change at 1.5 C. Science, 365(6459), 6974.

Huang, C., \& Deng, H. (2011). The model of developing low-carbon tourism in the context of leisure economy. Energy Procedia, 5, 1974-1978.

Jiang, P., Chen, Y., Xu, B., Dong, W., \& Kennedy, E. (2013). Building low carbon communities in China: The role of individual's behaviour change and engagement. Energy Policy, 60, 611-620.

Jim, C. (2015). Understanding Community Development. Retrieved from https://www.researchgate.net/ publication/265233282_Understanding_Community_Development

Jin, L. Q., \& Liu, R. (2009). Low-carbon economy and the transition of chinese economic development patterns. Inquiry into Economic Issues, 1, 84-87.

Kumar, S. Kusakabe, K. and Shrestha, P. (2016). Sustainable urban tourism through low-carbon initiatives: Experiences from Hue and Chiang Mai, 2016. Asian Institute of Technology; Nguyen Khanh Linh, Hue Center for International Cooperation; and Trinnawat Suwanprik, Municipality of Chiang Mai. Retrieved from https://www.indiaenvironmentportal.org.in/content/425524/sustainable-urban-tourismthrough-low-carbon-initiatives-experiences-from-hue-and-chiang-mai/

Kuo, N. W., Lin, C. Y., Chen, P. H., \& Chen, Y. W. (2012). An inventory of the energy use and carbon dioxide emissions from island tourism based on a life cycle assessment approach. Environmental Progress \& Sustainable Energy, 31(3), 459-465.

Kuo, N. W., \& Chen, P. H. (2009). Quantifying energy use, carbon dioxide emission and other environmental loads from island tourism based on a life cycle assessment approach. Journal of Cleaner Production, 17, 1324-1330. 
Lenzen, M., Sun, Y. Y., Faturay, F., Ting, Y. P., Geschke, A., \& Malik, A. (2018). The carbon footprint of global tourism. Nature Climate Change, 8(6), 522.

Li, J. H., Zhou, R. Z., \& Zhu, Y. B. (2013). Research on low-carbon tourism development in qinghai province of china based on stakeholder theory. Applied Mechanics and Materials, 291-294, 1429-1432.

Luo, J., \& Zhang, M. (2011). Route Choice of low-carbon industry for global climate change: an issue of China tourism reform. Energy Procedia, 5, 2283-2288.

Luo, Y., Wang, J., Dang, Q., \& Chen, Y. (2016, November). Literature Review on Low Carbon Eco-tourism. In 2016 rd International Conference on Management, Education Technology and Sports Science (METSS 2016). Atlantis Press.

McLennan, C. L. J., Becken, S., Battye, R., \& So, K. K. F. (2014). Voluntary carbon offsetting: Who does it? Tourism Management, 45(C), 194-198.

Mensin, S., Bhaktikul, K., Aroonsrimorakot, S., Krajangtimaporn, E., WannaProm, W., \& SinghBoon, P. (2018). The Study of Royal Project Community Development as Low Carbon and Sustainable Community Project, Highland Research and Development Institute (Public Organization). Bangkok: Chulalongkorn Unversity Press.

Michailidou, A. V., Vlachokostas, C., \& Moussiopoulos, N. (2015). A methodology to assess the overall environmental pressure attributed to tourism areas: A combined approach for typical all-sized hotels in Chalkidiki, Greece. Ecological Indicators, 50, 108-119.

Mulugetta, Y., \& Urban, F. (2010). Deliberating on low carbon development. Energy Policy, 38(12), 7546-7549.

Okoli, C., \& Pawlowski, S. D. (2004). The Delphi method as a research tool: an example, design considerations and applications. Information \& Management, 42(1), 15-29. https://doi.org/10.1016/j. im.2003.11.002.

Opoku, A., \& Ahmed, V. (2013). Understanding sustainability: a view from intra-organizational leadership within UK construction organizations. International Journal of Architecture, Engineering and Construction, 2(2), 133-143.

Peeters, P., \& Dubois, G. (2010). Tourism travel under climate change mitigation constraints. Journal of Transport Geography, 18(3), 447-457.

Rico, A., Martínez-Blanco, J., Montlleó, M., Rodríguez, G., Tavares, N., Arias, A., \& Oliver-Solà, J. (2019). Carbon footprint of tourism in Barcelona. Tourism Management, 70, 491-504.

Ridhosari, B., \& Rahman, A. (2020). Carbon footprint assessment at Universitas Pertamina from the scope of electricity, transportation and waste generation: Toward a green campus and promotion of environmental sustainability. Journal of Cleaner Production, 246, 119172.

Scheyvens, R. (1999). Ecotourism and the empowerment of local communities. Tourism Management, 20, 245-249.

Scott, D., Amelung, B., Becken, S., Ceron, J.P., Dubois, G., Gossling, S. (2016a). Climate change and tourism: responding to global challenges, 2008; Madrid, Spain: United Nations World Tourism Organisation (UNWTO), United Nations Environment Program (UNEP) and World Meteorological Organisation (WMO). Retrieved from https://www.unep.fr/scp/publications/details.asp?id=WEB/0142/PA

Scott, D., Gossling, S., Hall, C. M., \& Peeters, P. (2016). Can tourism be part of the decarbonized global economy? The costs and risks of alternate carbon reduction policy pathways. Journal of Sustainable Tourism, 24(1), 52-72.

$\mathrm{Su}$, J. (2019). Impact of tourism resource development based on low-carbon mode: a case study of Guizhou ethnic areas. Ecological processes, 8(1), 1-7.

Tang, Z., Shia, C. B., \& Liuc, Z. (2011). Sustainable development of tourism industry in china under the low-carbon economy. IACEED2010. Energy Procedia, 5, 1303-1307.

Tobelmann, D., \& Wendler, T. (2020). The impact of environmental innovation on carbon dioxide emissions. Journal of Cleaner Production, 244, 118787.

TSDF. (2018). The Royal Project Foundation. Retrieved from tsdf.or.th/en/ royally-initiated-projects/10757-the-royal-project-foundation/

Van Maanen, J. (1996). Ethnography. In A. Kuper \& J. Kuper (Eds.), The Social Science Encyclopedia (2nd ed., pp. 263-265). London: Routledge.

Wang, Q., Mao, Z., Xian, L., \& Liang, Z. (2019). A study on the coupling coordination between tourism and the low-carbon city. Asia Pacific Journal of Tourism Research, 24(6), 550-562.

Yuan, H., Zhoua, P., \& Zhoua, D. (2011). What is low-carbon development? A conceptual analysis. Energy Procedia, 5, 1706-1712. 
Zhang, J. (2017). Evaluating regional low-carbon tourism strategies using the fuzzy Delphi-analytic network process approach. Journal of Cleaner Production, 141, 409-419.

Ziglio, E., \& Adler, M. (1996). Gazing into the oracle: The Delphi Method and its application to Social Policy and Public Health. London: Jessica Kingsley Publishers.

Publisher's Note Springer Nature remains neutral with regard to jurisdictional claims in published maps and institutional affiliations. 